\title{
NÉMESIS (2010): LA EPIDEMIA DE POLIO EN UNA COMUNIDAD JUDÍA EN ESTADOS UNIDOS DURANTE LA SEGUNDA GUERRA MUNDIAL
}

\author{
Nemesis (2010): The Polio Epidemic in a Jewish Community in the United \\ States during World War II
}

\author{
Antonio PUJOL DE CASTRO \\ Facultad de Medicina. Universidad Complutense de Madrid (España). \\ Correo electrónico: apujol01@ucm.es
}

Fecha de recepción. 9 de septiembre de 2020

Fecha de aceptación: 19 de septiembre de 2020

Fecha de publicación: 29 de enero de 2021

\begin{abstract}
Resumen
Durante la epidemia de polio de Estados Unidos durante la Segunda Guerra Mundial, se cuenta la vivencia de la epidemia desde los ojos de un joven profesor de gimnasia en una comunidad judía. En el artículo describimos los aspectos principales de la epidemia. En primer lugar hablamos de las características que se dan al inicio de una epidemia, cuando se intenta llamar a la calma y se recuerdan enfermedades pasadas. A continuación se habla sobre el origen de la epidemia, las causas que se barajan y los sesgos racistas que pueden llegar a aparecer. También hablamos del rol del médico como fuente de conocimiento y como agente humanizador de la enfermedad. Hablamos del gobierno y las medidas poblacionales que se toman y la proporcionalidad de estas, abriendo el debate de hasta cuándo es responsable paralizar la vida cotidiana para controlar una enfermedad. Finalmente, hablamos del tratamiento de la polio, las grandes secuelas tanto físicas como psicológicas y la situación de la polio actualmente. Sin duda, la polio ha sido una epidemia ejemplar en cuanto a cómo combatir entre todos una amenaza común. Conocer su historia nos puede dar herramientas para enfrentarnos a las nuevas epidemias como la COVID-19.

Palabras clave: polio; epidemia; Estados Unidos; Segunda Guerra Mundial.
\end{abstract}




\title{
NÉMESIS (2010): LA EPIDEMIA DE POLIO EN UNA COMUNIDAD JUDÍA EN \\ ESTADOS UNIDOS DURANTE LA SEGUNDA GUERRA MUNDIAL \\ ANTONIO PUJOL DE CASTRO
}

\begin{abstract}
During the United States' polio epidemic during World War II, the experience of the epidemic is told from the point of view of a young gymnastics teacher in a Jewish community. Throughout the article we describe the main aspects of the epidemic. First, we talk about the characteristics that occur at the beginning of an epidemic, when you try to call to calm and remember past illnesses. It then discusses the origin of the epidemic, the causes that are being addressed and the racist biases that may emerge. We also talk about the role of the doctor as a source of knowledge and as a humanizing agent of the disease. We talk about the government and the population measures that are taken and the proportionality of them, opening the debate on how long it is responsible to paralyze daily life to control a disease. Finally, we talk about the treatment of polio, the great physical and psychological consequences and the situation of polio today. Without any doubt, polio has been an exemplary epidemic in terms of how to fight a common threat together. Knowing its history can give us tools to confront new epidemics such as COVID-19.
\end{abstract}

Keywords: polio; epidemy; United States; World War II.

\section{INTRODUCCIÓN}

En la mitología griega, Némesis es la diosa de la justicia retributiva, la solidaridad, la venganza, el equilibrio y la fortuna. Castigaba a los que no obedecían a aquellas personas con derecho a mandarlas y, sobre todo, a los hijos que no obedecían a sus padres. Recibía los votos y juramentos secretos de su amor y vengaba a los amantes infelices o desgraciados por el perjurio o la infidelidad de su amante ${ }^{1}$.

Con este título, Philip Roth ${ }^{2}$ hace referencia al acto de violencia que supone la epidemia de polio para una población. Durante el libro, el protagonista se plantea no solo la existencia de Dios, sino también la imperfección de este. ¿Qué clase de Dios permite que la polio mate y mutile a niños? Se llega a plantear incluso la posibilidad de que solo exista un genio maligno que sea el causante de todos nuestros males.

La poliomielitis fue descrita por primera vez por Michael Underwood en 1789. El primer brote fue descrito en Estados Unidos en 1843. En 1952, se describieron más de 21.000 casos de parálisis en Estados Unidos. Al inicio del siglo XX, pocas enfermedades daban más miedo a los padres de familia que la poliomielitis. La polio atacaba en los meses cálidos de verano, y cada cierto tiempo, las epidemias arrasaban las ciudades.
Aunque la mayoría de las personas se recuperaba rápidamente de la polio, algunas sufrían parálisis temporal o permanente, e incluso morían. Muchos supervivientes de la polio quedaban discapacitados de por vida, y eran un recordatorio, visible y doloroso para la sociedad, de las grandes cantidades de vidas jóvenes que cobraba la enfermedad ${ }^{3}$.

La polio es el nombre común de la poliomielitis, palabra proveniente de los vocablos griegos que significan gris y médula, lo cual hace referencia hacia la columna vertebral, y el sufijo itis, que significa inflamación. Poliomielitis, al abreviarse, se convirtió en polio. Por un tiempo, a la polio se le llamo parálisis infantil, aunque su efecto no era exclusivo para los más jóvenes ${ }^{3}$.

La polio está causada por el poliovirus, un enterovirus miembro del subgrupo de los picornavirus de RNA, como también lo son los rinovirus (causantes del resfriado común), los coxsackievirus (causantes de gran parte de las meningitis asépticas, la herpangina y la enfermedad mano, pie, boca) y el virus de la hepatitis $A^{4}$. Existen tres serotipos de Poliovirus, que presentan una mínima inmunidad cruzada entre ellos. El virus es rápidamente inactivado por el calor, el formaldehído, el cloro y la luz ultravioleta ${ }^{3}$.

El virus de la polio entra por la boca, se replica en la faringe y el tracto gastrointestinal. 


\section{NÉMESIS (2010): LA EPIDEMIA DE POLIO EN UNA COMUNIDAD JUDÍA EN \\ ESTADOS UNIDOS DURANTE LA SEGUNDA GUERRA MUNDIAL ANTONIO PUJOL DE CASTRO}

A continuación se expande a través de la sangre y los vasos linfáticos hasta llegar al sistema nervioso central. Allí, se extiende a través de las fibras nerviosas y destruye las motoneuronas.

Existen varias presentaciones ${ }^{3}$ :

- Polio asintomática: representa el $72 \%$ de los casos. No obstante, liberan virus activos a través de las heces que pueden infectar a otros.

- Polio leve: representa el $24 \%$ de los casos. Se presenta como una fiebre con malestar de garganta que se resuelve en una semana. No hay evidencia de invasión del sistema nervioso central.

- Polio no paralítica: se presenta como una meningitis aséptica (rigidez nucal y de los miembros inferiores), que termina en 2 a 10 días seguida de una recuperación completa.

- Polio paralítica: representa menos del $1 \%$ de los casos. Se produce después de una fase de pródromos febriles que dura 1 a 18 días. Tras esta fase, se produce la parálisis flácida. Los pacientes no experimentan pérdida de la sensibilidad ni de la cognición. Muchos pacientes se recuperan completamente de la parálisis, y en la mayoría, recuperan la función de forma variable. La parálisis que dura más de 12 meses suele ser permanente. La mortalidad de la polio paralítica es de $2 \%-5 \%$ en niños, y de $15 \%-30 \%$ en adultos, llegando al $25 \%-75$ $\%$ si implica las estructuras bulbares (pares craneales) y al músculo diafragma.

En cuanto a su epidemiología, el reservorio del virus son los humanos, y su transmisión es fecal-oral. La transmisión es más frecuente 7-10 días antes o después de la aparición de los síntomas, y los virus están presentes en las heces durante 3-6 semanas.

A continuación, haremos referencia a algunos aspectos relacionados con la enfermedad y su representación en el libro.

\section{EL INICIO DE UNA EPIDEMIA}

"El primer caso de polio de aquel verano se produjo a comienzos de junio, poco después del Día de los Caídos, en un barrio italiano pobre que estaba en el otro extremo de la población donde nosotros vivíamos. [...] Hubo que esperar a la festividad del Cuatro de Julio, cuando ya se habían registrado cuarenta casos en la ciudad, para que en la primera plana del periódico vespertino apareciera una noticia titulada "Las autoridades sanitarias alertan a los padres sobre la polio", donde se citaba al doctor William Kittell, inspector del Consejo de Sanidad, quien había prevenido a los padres para que observaran detenidamente a sus hijos y, en caso de que un niño mostrara síntomas como dolor de cabeza, garganta irritada, náuseas, rigidez de cuello, dolor en las articulaciones o fiebre se pusieran en contacto con el médico".

Con estas palabras empieza el relato. Una ficción que bien podría haber sido la realidad de un observador en el verano del año 1944 en una comunidad judía en Estados Unidos. Como al inicio de cualquier epidemia, las autoridades dan un primer aviso e incitan a la población a estar alerta sobre la aparición de los posibles brotes.

"Aunque el doctor Kittell reconocía que cuarenta casos de polio eran más del doble de los que solían producirse al comienzo de la temporada, quería dejar claro que aquella ciudad de 429.000 habitantes en modo alguno sufría lo que podría considerarse una epidemia de poliomielitis".

Por una parte, las autoridades tienen la obligación de informar y ser transparentes con la población a la que sirven. Por otra parte, tienen que medir la cantidad y la forma en la que presentan sus palabras para evitar que cunda el pánico colectivo ${ }^{5}$.

Ante la nueva enfermedad, los ancianos no pueden dejar de recordar epidemias previas:

"La abuela también recordaba que a los pacientes de tos ferina se les exigía que se pusieran brazaletes y que, antes de que se encontrara

Rev. Med. Cine. 2020; 16 (e), 435-444 Ediciones Universidad de Salamanca / @@@ J. Med. Mov., 2020; 16 (e), $435-444$ 


\section{NÉMESIS (2010): LA EPIDEMIA DE POLIO EN UNA COMUNIDAD JUDÍA EN \\ ESTADOS UNIDOS DURANTE LA SEGUNDA GUERRA MUNDIAL ANTONIO PUJOL DE CASTRO}

la vacuna, la enfermedad más temida en la ciudad era la difteria. Recordaba haber recibido una de las primeras vacunas antivariólicas".

La tos ferina es una enfermedad provocada por la bacteria Bordetella pertussis que afecta típicamente a los infantes menores de un año provocando una tos intensa que llega a provocar gallos inspiratorios. La bacteria inmoviliza los cilios en la vía respiratoria, provocando acúmulo de moco, atelectasias pulmonares y disminución de la oxigenación. Además, produce efectos sistémicos a través de la producción de la toxina pertusoide. La enfermedad es conocida desde el siglo XVI, pero no se desarrolló la vacuna hasta el año $1920^{6}$.

La difteria es una enfermedad causada por la bacteria Corynebacterium diphtheriae, un patógeno estrictamente humano que no se aísla con frecuencia pero que causa una enfermedad importante, mediada por la toxina diftérica. La difteria se presenta como una enfermedad respiratoria con un cuadro de faringitis exudativa, con la formación de una pseudomembrana gruesa en la faringe. Puede llegar a provocar disnea, parálisis y muerte ${ }^{7}$. La enfermedad es conocida desde el año 1613, año conocido en España como El año de los Garrotillos ${ }^{8}$. En 1890, se descubrió la inmunización contra la difteria utilizando el toxoide, y se creó la antitoxina a partir del plasma de animales inmunizados.

Actualmente la inmunización contra la tos ferina y contra difteria se administran conjuntamente contra el tétanos en una vacuna trivalente: DTPa, que contiene el toxoide diftérico, el toxoide tetánico y un componente de Bordetella pertussis con la célula entera o de pared completa (DTPe), o con componente acelular de Bordetella pertussis (DTPa) ${ }^{9}$.

La viruela fue una enfermedad infecciosa grave producida por el virus de la viruela. La enfermedad se manifestaba como erupciones cutáneas que evolucionaban a llagas, luego a pústulas y finalmente a costras que caían. La enfermedad iba asociada a fiebre y vómitos, y dejaba cicatrices por todo el cuerpo, provocando ceguera o la muerte. Se desconoce el origen de la viruela, pero existe evidencia de ser una enfermedad presente en las momias egipcias datadas del siglo III a.C. Durante el siglo XVI en China se practicaban inoculaciones que mitigaban los efectos de la viruela. En 1796, Edward Jenner creó la primera vacuna moderna, y finalmente en 1980 se consiguió convertir en la primera enfermedad infecciosa que el ser humano ha logrado erradicar ${ }^{10}$.

\section{EL ORIGEN DE LA EPIDEMIA}

Con la evolución de la epidemia, la población empieza a buscar un agente causal. En estos momentos de crispación social, los grupos étnicos minoritarios pueden ser víctimas de un racismo hasta el momento encubierto. En el libro se expone el ejemplo de los judíos y de los italianos. En el caso de los italianos, son los judíos del barrio más afectado quienes les culpan:

"- Pero ¿qué me dice de los italianos? iTienen que haber sido los italianos!".

"- Quienes lo han traído son esos cabrones italianos".

Del mismo modo, los propios judíos también son señalados como causantes de la epidemia.

"Los antisemitas dicen que es por culpa de los judíos que la polio se propague en esa zona. [...] Se diría que algunos creen que la mejor manera de librarse de la epidemia sería quemar Weequahic con todos los judíos dentro".

Otro riesgo de la epidemia es la apofenia, donde la población ve patrones, conexiones 0 ambos en sucesos aleatorios o en datos sin sentido. Este hecho lleva a culpar a la tienda de perritos calientes de ser la causa de la epidemia en el barrio:

"- No, no viene nadie debido a ese chico. [...] Se comió aquí un perrito caliente y entonces fue a su casa, cogió la polio y murió, y ahora todo el mundo teme entrar en el local. [...] Los vendemos a miles, y nadie pilla la polio". 


\section{NÉMESIS (2010): LA EPIDEMIA DE POLIO EN UNA COMUNIDAD JUDÍA EN \\ ESTADOS UNIDOS DURANTE LA SEGUNDA GUERRA MUNDIAL \\ ANTONIO PUJOL DE CASTRO}

En el libro se plantea una cuestión que incluso una persona que estudia la epidemiología de la enfermedad se puede llegar a preguntar:

"¿Por qué la polio solo ataca en verano?".

En el libro, esta pregunta se responde acusando al calor.

"[...] no pudo por menos que preguntarse si el mismo sol veraniego no sería el causante de la polio. A mediodía, cuando caía a plomo, el sol parecía tener fuerza suficiente para paralizar y matar $[\ldots] "$.

Esta cuestión no tiene respuesta. Se ha visto que el patrón estacional tiene un pico en los meses de verano y otoño en los climas templados, mientras que la transmisión remite con las primeras heladas. En los climas tropicales las diferencias estacionales son mucho menos pronunciadas $^{11}$.

\section{EL PAPEL DEL MÉDICO}

En el libro se deja entrever la figura del Dr. Steinberg, el padre de la novia del protagonista. Con esta descripción se pone de manifiesto la relevancia del humanismo en la identidad médica.

"[...] el doctor Steinberg era un hombre culto [...] el señor Cantor [el protagonista] siempre estaba seguro de que cuando hablaba sabía lo que se decía. [...] no solo era una maravilla con los pacientes, sino que tenía el don de satisfacer a todos los miembros de la familia y de resolver de una manera justa las disputas de sus hermanas menores. Era el mejor psicólogo que había conocido jamás. «Mi madre -afirmó- le llama "el impecable termómetro de la temperatura emocional de la familia". No conozco a ningún médico que sea más humano que papá".

A lo largo del relato, la figura del médico, si bien no juega un papel relevante en el desarrollo de la trama ni en el control de la epidemia, es mirado con frecuencia por los personajes, tanto para buscar conocimiento como para buscar consuelo.
"Verás, hay muy pocas probabilidades de que seas un portador infectado sano. Aunque eso podría suceder, sería una anormalidad muy infrecuente. En general, la etapa de portador coincide con la etapa clínica. Sin embargo, para que te quedes del todo tranquilo, deberíamos hacerte una punción lumbar y extraer un poco de líquido espinal para analizarlo. Ciertos cambios en ese líquido son indicativos de polio".

Es evidente que la relación médico-paciente, en sí misma, aporta una mejoría terapéutica indiscutible, acompañando el sufrimiento y el bienestar, mejorando la orientación diagnóstica y reduciendo la necesidad de pruebas complementarias. También contribuye de forma importante a una mayor y más consciente adherencia del paciente al tratamiento, una vez que este se siente implicado y acompañado en la toma de decisiones. Aun así, la relación médico-paciente no es solo una herramienta, es un valor en sí mismo y un elemento humanizador ${ }^{12}$.

\section{EL GOBIERNO Y LAS POLÍTICAS DE SALUD PÚBLICA}

En el libro no se menciona ninguna acción concreta de la administración durante el primer tercio del relato. Cuando finalmente se plantean las medidas que ha tomado el gobierno local, choca ver que estas medidas son muy dirigidas hacia una causa sobre la que no hay evidencia de que sea la causa real, en este caso las moscas.

"[...] las medidas que había tomado el Ayuntamiento para que las basuras y todo rastro de suciedad se eliminaran regularmente de las propiedades públicas y privadas. Les recordó que debían tener bien tapados los cubos de basura y participar en la campaña "Acabemos con las moscas» [...] iba a aumentarse la frecuencia de la recogida de basura, que tendría lugar cada dos días, y, a fin de ayudar a la campaña contra las moscas, unos «inspectores sanitarios» visitarían los barrios residenciales para asegurarse de que todas las calles estaban libres de desecho y distribuirían matamoscas gratuitamente". 


\section{NÉMESIS (2010): LA EPIDEMIA DE POLIO EN UNA COMUNIDAD JUDÍA EN \\ ESTADOS UNIDOS DURANTE LA SEGUNDA GUERRA MUNDIAL \\ ANTONIO PUJOL DE CASTRO}

El alcalde incluso llega a hacer declaraciones llenas de seguridad que parecen más destinadas a guardar las apariencias en vez de estar basadas en la evidencia científica:

"[...]Por encima de todo, mantengan limpios 10 patios y los sótanos, no pierdan la cabeza y pronto veremos que la propagación de este azote va menguando. Y maten las moscas sin piedad. Nunca hay que subestimar el daño que hacen las moscas".

Entre las enfermedades que pueden transmitir las moscas se incluyen las infecciones entéricas (como disenterías, diarreas, tifoideas, cólera y algunos helmintos), oculares (como tracoma o conjuntivitis epidémica) y cutáneas (como el pian producido por el treponema no sifilítico Treponema pallidum subsp pertenue, la difteria cutánea, algunas micosis y la lepra). Es interesante saber que la poliomielitis también puede ser transmitida por moscas ${ }^{13}$.

El papel del gobierno es complicado durante las crisis. Por una parte, tiene que llamar a la calma de la población para evitar el pánico colectivo y el malestar psicológico de la población. No decir toda la verdad puede evitar de manera eficaz una oleada de pánico que podría dar lugar a más víctimas ${ }^{5}$. No obstante, el gobierno también ha de ser transparente en sus acciones y sus conocimientos, y saber basar su toma de decisiones en argumentos objetivos $y$ referenciables.

Una vez instaurada la nueva epidemia, la población empieza a plantear sus ideas sobre cómo se puede prevenir la enfermedad:

"-¿¿Por qué no fumigan?- planteó otra voz-. ¿Por qué no usan desinfectante? Que lo desinfecten todo.

- ¿Por qué no hacen lo que hacía en mi infancia? Nos daban bolas de alcanfor alrededor del cuello. Había una cosa que olía mal llamada asafétida. A lo mejor eso sería útil ahora.

- ¿ ¿Por qué no extienden alguna sustancia química por las calles y matan al germen de esa manera?
- Olvídense de las sustancias químicas -dijo otra vecina-. Lo más importante es que los niños se laven las manos, que se las laven continuamente. iLimpieza! iLa limpieza es la única cura!".

"Hay quien pide que se imponga la cuarentena en Weequahic [...] cerrarían con barricadas para que nadie pudiera entrar ni salir. [...]".

La toma de decisiones en salud pública es un proceso que implica que los gobiernos puedan responder a las circunstancias cambiantes, anticipando las amenazas emergentes e identificando formas de controlarlas. Las decisiones de salud pública han de ser un producto de calidad de las pruebas, discusión y deliberación, considerando a parte de la evidencia científica los valores, las preferencias y los aspectos legales, éticos y sociales ${ }^{14}$.

A pesar de la cuarentena y otras medidas de control de la dispersión de la enfermedad, la vida ha de continuar, y en el libro se plantea el dilema que también hemos vivido durante la epidemia de SARS-CoV2: abrir las escuelas o dejarlas cerradas.

"Van a cerrar todos los sitios donde se reúnen niños. [...] Los niños menores de dieciséis no podrán ir al cine. Cierran la piscina municipal, la biblioteca con todas sus sucursales y las escuelas dominicales. [...] es posible que las escuelas no abran a comienzos de curso. [...]".

En el caso concreto de la epidemia actual de COVID-19, a pesar de que aún hay varias preguntas sin responder sobre la relación entre niños y COVID-19, existe evidencia de que tienen un riesgo menor de adquirir y transmitir la infección que los adultos y tienen un riesgo significativamente menor de presentar la enfermedad grave ${ }^{15}$. No obstante, el dilema entonces con la epidemia de polio y ahora con la COVID-19 es el mismo: la cuarentena y el cierre de colegios puede tener consecuencias negativas en los niños afectando su vida social, su educación y su salud mental. Varios países están probando distintas 


\section{NÉMESIS (2010): LA EPIDEMIA DE POLIO EN UNA COMUNIDAD JUDÍA EN \\ ESTADOS UNIDOS DURANTE LA SEGUNDA GUERRA MUNDIAL \\ ANTONIO PUJOL DE CASTRO}

estrategias para poner medidas de contención de distanciamiento social, reorganización de las clases en grupos más pequeños, higienización de los espacios, muebles y juguetes, identificación temprana de casos, en el entorno escolar y en su rastreo. De este modo, los gobernantes han de valorar los beneficios y los perjuicios de su estrategia de reapertura, y las posibles diferencias e inequidades socioeconómicas que podían ampliarse si se mantienen los colegios cerrados ${ }^{16}$.

\section{EL TRATAMIENTO, LA REHABILITACIÓN Y LAS SECUELAS}

Dado que no existe un tratamiento específico, la terapia convencional de la poliomielitis se basa en medidas de soporte como reposo, analgesia y antipiréticos a demanda. No existe un tratamiento antiviral adecuado. Durante la mielitis activa han de tomarse medidas para evitar úlceras de contacto, trombosis venosa profunda, atelectasias pulmonares e infecciones urinarias y contracturas por la inmovilidad prolongada. En caso de que haya afectación diafragmática, puede ser necesaria la asistencia respiratoria mecánica ${ }^{17}$.

"[...] el tratamiento por medio de compresas calientes, junto con dolorosos estiramientos de los músculos contraídos de los brazos, las piernas y la espalda -que la parálisis había torcido-, a fin de "rehabilitarlos». [...] fue recuperando gradualmente el uso del brazo derecho y el uso parcial de las piernas, aunque le quedó torcida la parte inferior de la espina dorsal y varios meses después hubo que corregirla mediante una fusión quirúrgica, un injerto óseo y la inserción de variIlas metálicas fijadas a la espina dorsal. [...] Al cabo de unas semanas lo sentaron en una silla de ruedas, y la utilizaba cuando regresó a Newark. [...] con el tiempo, recuperó por completo la función muscular de la pierna derecha. Sus facturas eran astronómicas, ascendían a muchos millares de dólares, pero las pagaban el Instituto Hermana Kenny y la organización March of Dimes".
Tras la infección inicial el paciente presenta un periodo de aproximadamente un año de recuperación funcional hasta un nivel que se suponía estable durante toda la vida. No obstante, la enfermedad presenta una serie de síntomas tardíos: fatiga, debilidad muscular, artromialgias, calambres, intolerancia al frío, insomnio, que constituyen el síndrome postpolio, con una nueva e incrementada debilidad muscular progresiva en territorios no afectos que aparece entre 15 y 40 años después de la infección. El mecanismo etiopatogénico es desconocido así como su prevalencia, estimada entre el 20 al $85 \%$ de personas afectadas. El síndrome postpolio afecta severamente a la calidad de vida de las personas, existiendo un importante infradiagnóstico, con un alto impacto emocional en pacientes y familiares ${ }^{18}$.

En el libro se hace referencia a la March of Dimes (Procesión de las monedas de diez centavos). En el año 1938, el presidente estadounidense Franklin Delano Roosevelt fundó esta organización en respuesta a la epidemia de polio. El propio Roosevelt había sido diagnosticado con polio en el año 1921, a pesar de que posteriormente se ha valorado que sus síntomas eran más típicos del síndrome Guillain-Barré. La fundación era una alianza entre científicos y voluntarios para recolectar dinero para patrocinar la investigación y la protección social de aquellos afectados por la enfermedad. Miles de personas enviaron cartas con monedas de diez centavos a la Casa Blanca. Con este esfuerzo se llegaron a recaudar 85.000 dólares americanos $^{19}$. Actualmente, una vez controlada la polio en Estados Unidos, la fundación se dedica a la concienciación y la prevención de la prematuridad en las gestaciones, uno de los mayores problemas de salud a nivel mundial ${ }^{20}$.

En el libro también se hace referencia al impacto social y psicológico de las secuelas. A parte de hablar de las modificaciones que las viviendas necesitan recibir para que los afectados puedan manejarse con las sillas de ruedas, 


\section{NÉMESIS (2010): LA EPIDEMIA DE POLIO EN UNA COMUNIDAD JUDÍA EN \\ ESTADOS UNIDOS DURANTE LA SEGUNDA GUERRA MUNDIAL \\ ANTONIO PUJOL DE CASTRO}

también habla del impacto que tiene en sus vidas sentimentales:

"La parálisis y todas sus secuelas habían dañado irremediablemente la seguridad en sí mismo y en su virilidad, y se había retirado por completo de esa faceta de la vida. Se consideraba asexuado, una especie de cartucho de fogueo, una valoración que no podía resultar más humiIlante para un muchacho que había alcanzado la mayoría de edad en una época de sufrimiento y conflictos para la población estadounidense, cuando los hombres debían ser impertérritos defensores del hogar y del pais".

La sexualidad es algo fundante que nos permite ser, reconocernos del otro, con el otro y como hombre o mujer. Se diferencia de la genitalidad y la sobredimensiona. Somos seres sexuados desde el mismo momento del nacimiento. La sociedad atribuye una serie de mitos a las personas que viven con una discapacidad: no tienen sexualidad, no les interesa, sus dificultades les impiden tener relaciones "normales", no tienen atractivo ni capacidad de producir placer, que todas las personas con discapacidad son heterosexuales, que no necesitan educación afectivo-sexual o que la única forma correcta y placentera de obtener placer sexual es mediante el coito. Estos mitos impactan negativamente en la sexualidad de la persona, silenciando e invisibilizando la diversidad, considerando innecesaria la educación sexual y por tanto, evitando y reprimiendo el pleno ejercicio de sus derechos sexuales y reproductivos ${ }^{21}$.

Además, los roles de género juegan un papel en la psicología de la persona con discapacidad. La sociedad plantea en su imaginario colectivo unas características y un rol específico para cada género. Como miembros de la sociedad, participamos de este imaginario colectivo y tenemos integradas unas expectativas de cómo debe ser un hombre o una mujer. La incapacidad de ceñirse a estas expectativas genera malestar, sufrimiento y dolor ${ }^{22}$.
Finalmente en el libro se hace referencia al fin de la fase más crítica de la epidemia con la aparición de la vacuna.

"[...] tuvimos la mala suerte de enfermar once años antes de que descubrieran la vacuna. [...] Hoy los niños están absolutamente libres de preocupaciones durante las vacaciones de verano, como debe ser".

Existen dos tipos de vacuna para la polio:

- Oral atenuada (Sabin): esta vacuna contiene virus que han sido atenuados para que no produzca la enfermedad. Presenta varios beneficios: es oral, por lo que no hay que invertir en jeringuillas ni material que necesite ser desinfectado rigurosamente, además, es mejor tolerada por los pacientes que una inyección; el estar en el tracto digestivo, parte es eliminada por las heces, por lo que existe la posibilidad de que otras personas también se inmunicen si no hay un adecuado manejo de las aguas residuales. Esta cualidad ha hecho que sea la vacuna más utilizada en países empobrecidos, ya que se consigue una alta cobertura de la inmunización. No obstante, tiene un riesgo: el virus atenuado puede reactivarse y causar poliomielitis.

- Intramuscular inactivada (Salk): esta vacuna no contiene virus, sino parte de ellos, por lo que no pueden producir la enfermedad ni contagiarse. Solamente está protegida la persona que ha sido vacunada.

La tendencia actual de vacunación en los países enriquecidos es usar la vacuna de polio intramuscular inactivada, mientras que en los países empobrecidos se utiliza la vacuna oral atenuada. En estos países empobrecidos, se ha llegado incluso contraindicar la vacuna intramuscular, buscando la protección fecal-oral que ofrece la vacuna oral. No obstante, la vacuna oral tiene el riesgo de provocar poliomielitis por la reactivación del virus (vaccine derived poliovirus, 


\section{NÉMESIS (2010): LA EPIDEMIA DE POLIO EN UNA COMUNIDAD JUDÍA EN ESTADOS UNIDOS DURANTE LA SEGUNDA GUERRA MUNDIAL ANTONIO PUJOL DE CASTRO}

VDPV). Esta situación ha provocado que en el año 2017 ocurriesen 22 casos de polio, mientras que el número de casos de VDPV fuese de 96. Ante esta situación, se ha visto que el objetivo a nivel mundial es que todos los países tengan los medios para poder vacunar con la vacuna intramuscular y así poder erradicar tanto la polio salvaje como la VDPV ${ }^{23}$.

La incidencia de poliomielitis paralítica secundaria a la vacuna oral es de 3,8 por millón de casos, mientras que por una cepa de polio salvaje, se produce parálisis en 1 de cada 200 casos. Esta enorme diferencia justifica el uso de la vacuna oral a pesar de su riesgo ${ }^{24}$.

A nivel global, la polio se ha llegado a considerar como la próxima enfermedad infecciosa a erradicar. Los esfuerzos de vacunación han llegado a erradicar la polio en casi todo el mundo, excepto en tres países donde todavía sigue siendo un problema: Pakistán, Afganistán y Nigeria. Ha ocurrido algún brote en algunos países en conflicto bélico como Somalia, Etiopía y Siria. Algunas barreras para completar la erradicación son el pobre acceso a la sanidad en zonas remotas endémicas. Gracias a la vacunación rutinaria infantil se ha conseguido reducir en un 99 \% la incidencia global, pasando de 350.000 casos anuales en 1988 a tan solo 33 en $2018^{24}$.

Sin duda, la historia de la polio es una historia convincente del valor de las vacunas. Se suele decir de las vacunas que son "malas embajadoras de su importancia", ya que cuanto más se utilizan, hay menos enfermedad y por tanto menor percepción de riesgo que lleva a desconfiar de la necesidad de la vacuna. No obstante, historias como la contada en Nemesis nos ayudan a reflexionar sobre cómo una enfermedad ahora marginal ha llegado a ser uno de los mayores azotes a nivel global hace tan solo 70 años.

\section{REFERENCIAS}

1. Wikipedia contributors. March of Dimes. Wikipedia, The Free Encyclopedia [Internet]. August 7, 2020, [Consultado el: 6 de Septiembre de 2020].

2. Roth P. Nemesis. Barcelona: Anagrama; 2010.

3. Centers for Disease Control and Prevention. Poliomyelitisc. cdc.gov [Internet]. 2015 [Consultado el: 5 de septiembre de 2020].

4. Murray PR. Microbiología médica básica. Barcelona: Elsevier; 2018. p. 93-98.

5. Zizek S. Pandemia. La covid-19 estremece al mundo. Anagrama; 2020.

6. Murray PR. Microbiología médica básica. Barcelona: Elsevier; 2018. p. 40-51.

7. Murray PR. Microbiología médica básica. Barcelona: Elsevier; 2018. p. 25-32.

8. Laval E. El garotillo (difteria) es España (siglos XVI y XVII). Rev Chil Infect. 2006; 23(1):78-80.

9. Asociación Española de Vacunología. Vacunas combinadas. Vacunas.org [Internet]. 2018. [Consultado el: 5 de septiembre de 2020].

10. Centers for Disease Control and Prevention. History of Smallpox . cdc.gov [Internet]. 2016 [Consultado el: 5 de septiembre de 2020].

11. Kew OM, Sutter RW, Gourville EM, Dowdle WR, Pallansh MA. Vaccine-derived polioviruses and the endgame strategy for global polio eradication. Annu Rev Microbiol. 2005;59:587-635.

12. Foro de la Profesión Médica de España. La Relación Médico Paciente. Patrimonio Inmaterial de la Humanidad. Madrid: Consejo General de Colegios Oficiales de Médicos; 2017.

13. Nazari M, Mehrabi T, Hosseini SM, Alikhani MY. Bacterial contamination of adult house flies (Musca domestica) and sensitivity of these bacteria to various antibiotics, captured from Hamadan City, Iran. J Clin Diagn Res. 2017;11(4):DC04-DC07. 


\section{NÉMESIS (2010): LA EPIDEMIA DE POLIO EN UNA COMUNIDAD JUDÍA EN ESTADOS UNIDOS DURANTE LA SEGUNDA GUERRA MUNDIAL ANTONIO PUJOL DE CASTRO}

14. Cediel-Becerra NM, Krause G. Herramientas para la toma de decisiones en salud pública basadas en la evidencia y priorización de enfermedades. Rev Salud Pública. 2013;15(5): 694-706.

15. Sheikh A, Sheikh A, Sheikh Z, Dhami S. Reopening schools after the COVID-19 lockdown. J Glob Health. 2020; 10(1): 010376.

16. Fantini MP, Reno C, Biserni GB, Savoia E, Lanari M. COVID-19 and the re-opening of schools: a policy maker's dilemma. Ital J Pediatr. 2020;46(79).

17. Tesini BL. Poliomielitis. Manual MSD [Internet.; 2019 [Consultado el: 6 de septiembre de 2020.]

18. Muñoz Cobos F, Morales Sutil ML, Faz García MC, Ariza González M, Salazar Agulló JA, Burgos Varo ML. Polio y postpolio. Visión de pacientes y profesionales en atención primaria. Rev Esp Salud Publica. 2018;92: e201806035.

19. Wikipedia contributors. March of Dimes. Wikipedia, The Free Encyclopedia [Internet]. August 7, 2020, [Consultado el: 6 de septiembre de 2020].
20. March of Dimes Who we are. March of Dimes [Internet].; c2020 [Consultado el: 6 de septiembre de 2020].

21. Iglesias P. La sexualidad en las personas con discapacidad [Internet]. Asociación Síndrome de Down de la República Argentina; [Internet]. 6 de septiembre de 2020. [Consultado el: 6 de septiembre de 2020.]

22. Waisblat A, Sáenz A. La construcción sociohistórica de los roles masculino y femenino. Patriarcado, capitalismo y desigualdades instaladas. Revista Sexología y Sociedad. 2014;19(2):172-94.

23. John TJ, Dharmapalan D. The moral dilemma of the polio eradication programme. Indian J Med Ethics. 2019;4(4):294-7.

24. Wolbert JG, Higginbotham K. Poliomyelitis (Polio) [Actualizado 2020 Jun 22]. En Treasure Island (FL) StatPearls Publishing; 2020-. [Consultado el: 6 de septiembre de 2020].

\begin{tabular}{ll|} 
Estudiante de Medicina. Universidad Complutense de Madrid (UCM). Pro- \\
moción de 2015-2021. Secretario General del \\
Consejo Estatal de Estudiantes de Medicina (CEEM) en 2017-2019. Presi- \\
dente del CEEM en 2019-2020.
\end{tabular}

